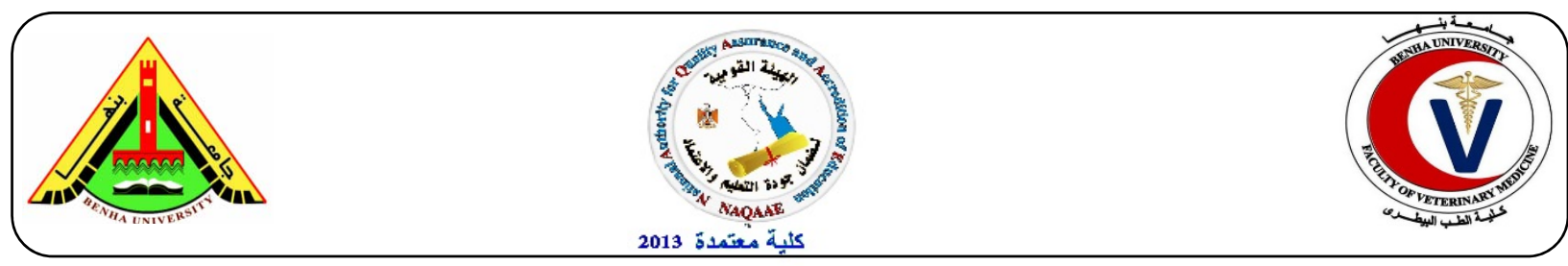

\title{
Biochemical effects of spirulina platensis against oxidative stress caused by doxorubicin
}

\author{
Mohamed R. Hassanen ${ }^{1}$, Mohamed K. Mahfouz ${ }^{1}$, Ayman S. Farid ${ }^{2}$, Ahmed H. Fadlullah \\ ${ }^{1}$ Department. Of Biochemistry, ${ }^{2}$ Department. Of Clinical Pathology, Fac. of Vet. Medicine, Benha \\ University, Egypt.
}

\begin{abstract}
A B S T R A C T
Doxorubicin (DOX ) is an anthracycline derivative antibiotic, used as anticancer agent, it causes generation of free radicals and induces oxidative stress, associated with cellular injury and participate in hepatonephrotoxicity in normal human cells . The protective effect of Spirulina Platensis (SP) , $a$ filamentous blue green algae, on Doxorubicin induced oxidative stress and hepatotoxicity was evaluated in male rats. Oral administration of water extract of Spirulina $(1000 \mathrm{mg} / \mathrm{kg} / \mathrm{b} . \mathrm{wt})$ for six weeks following an acute toxic dose of Doxorubicin $(1.0 \mathrm{mg} / \mathrm{kg} / \mathrm{b}$.wt $)$, reduces the hepatotoxicity and attenuates doxorubicin-induced stress .The post-treatment with Spirulina reduces the activity of Liver marker enzymes such as serum alanine aminotransferase (ALT), Aspartate aminotransferase (AST) and Renal function disorders represented by urea. The ratio of decrease were lower in the first three weeks if compared with the last three weeks. On the other hand, Oral administration of Spirulina extract for six weeks following an acute toxic dose of Doxorubicin, led to an obvious increase in the activity of antioxidant Parameters including Catalase ( CAT ) and Super Oxide Dismutase ( SOD ). The results clearly demonstrate that Spirulina treatment augments the antioxidants defense mechanism in Dox induced toxicity and provides evidence that it may have a therapeutic role in free radical mediated diseases.
\end{abstract}

Keywords: Doxorubicin (DOX), Spirulina Platensis (SP), Oxidative stress

(http://www.bvmj.bu.edu.eg)

(BVMJ-28(2): 147-154, 2015)

\section{INTRODUCTION}

$\mathrm{T}$ The main problem of anticancer drugs is that they target not only the tumored, but also other normal cells, thus causing the same damage to both normal and abnormal cells (GranadosPrincipal et al., 2010). Doxorubicin, an anthracycline antibiotic, is one of the most widely used anticancer drugs. The main anticancer action of Doxorubicin is believed to involve DNA damage through inhibition of topoisomerase II (Quiles et al., 2002). Doxorubicin induces the generation of free radicals and the induction of oxidative stress, associated with cellular injury (Injac et al., 2008). The free radical generation by Doxorubicin may participate in cardiotoxicity and genotoxicity in normal human cells (Quiles et al., 2002). However its use in chemotherapy has been limited largely due to its diverse toxicities, including cardiac, hepatic, hematological and testicular toxicity [Gillick et al., 2002, Yilmaz et al., 2006]. DOX increases the apoptotic processes in liver tissue [Pedrycz et al., 2005], induces lipid peroxidation in microsomes and mitochondria especially in the presence of $\mathrm{Fe}^{3+}$ ions and include focal, vascular damage and stenosis in hepatocytes (Pedrycz et al., 2004). Many plant products are increasingly recognized as having protective role in coronary artery disease and stroke through several mechanisms including antioxidant and hypocholesterolemic properties (Bopanna et al., 1997). Spirulina potentiate the immune system leading to suppression of 
cancer development and viral infection (Hirahashi et al., 2002). It has direct effect on reactive oxygen species. Spirulina as many other Cyanobacteria species have the potential to produce a large number of antimicrobial substances, so they are considered as suitable candidates for exploitation as biocontrol agents aganist plant pathogens. Blue green alga, Spirulina is well-known to have anti-bacterial and anti-fungal activities (Kulik, 1995). The antioxidant activity of Spirulina was attributed to phycocyanin, $\beta$-carotene, tocopherol, $\gamma$-linolenic acid and phenolic compounds (Chopra et al., 2008). For instance, selenium-containing phycocyanin from Spirulina has been shown to have a strong scavenging activities against superoxide and hydrogen peroxide radicals (Huang et al., 2007). Spirulina contains an important enzyme superoxide dismutase (SOD) (1700 units/g of dry mass) that acts indirectly by slowing down the rate of oxygen radical generating reactions (Belay, 2002). It also have protective effects against oxidative stress induced by lead acetate in the liver and kidney of rats (Ponce-Canchihuamanet et al., 2010). Feeding of Spirulina also reduces hepatoxicity induced by cadmium in rats and the effect is suggested to be mediated through its antioxidant properties (Karadeniz et al., 2009). Spirulina is also known to have protective effects against nephrotoxicity due to oxidative damage induced by gentamicin (Karadeniz et al., 2008). Spirulina has hypocholesterolemic effects when administrated in humans ( 4.2 g.day ${ }^{-1}$ ) for 4 weeks. (Nakaya et al., 1988). Radiation protection offered by Spirulina may be due to the phytopigments carotenoids, chlorophyll, phycocyanin as well as polysaccharides in Spirulina. (Datla et al., 2011). The aim of the present Study was to examine the possible potential effects of Spirulina against hepatic and nephrotic intoxication induced by Doxorubicin $\mathrm{HCl}$ in adult male rats in an attempt to pave the way for the possibility to use it for therapeutic application as evidenced by measuring the levels of enzyme activities; (AST, ALT), ( CAT, SOD ) and blood urea nitrogen (BUN).

\section{MATERIAL AND METHODS}

\subsection{Materials:}

Sixty male albino rats weighting 200-225 g (age of rat 50-60 days) were used in the experimental investigations of this study. Rats were obtained from the Research Institute of Ophthalmology, Giza, Egypt. The animals were housed in 49x35 cm stainless steel wire mesh cages with a bedding of ground wood chips at $21^{\circ} \mathrm{C}$. They were fed fresh-pelleted food and their water as placed in glass bottles of $500 \mathrm{ml}$. Rats were kept at a constant environmental and nutritional condition throughout the period of experiment. The animals were left for 7 days for acclimatization before the beginning of the experiment.

\subsection{Drugs and Chemicals :}

Preparation of drugs before administration: Each $10 \mathrm{mg}$ of Doxorubicin dissolved in 5 $\mathrm{ml}$ of distilled water. Each $1 \mathrm{ml}$ of aqueous solution contains $0.5 \mathrm{mg}$ of Doxorubicin. Spirulina platensis powder dissolved in water, $1000 \mathrm{mg} / \mathrm{kg} / \mathrm{b}$. w. Doxorubicin $\mathrm{HCl}$ Red - Coloured Solution ( $10 \mathrm{mg} /$ Vial ) dissolved in ( $10 \mathrm{ml}$ Saline Solution ). Kits of Plasma Color metrical evaluation of T. P. Kits of Colorimetric evaluation of AST, ALT and Catalase (CAT) assayed by determining of the rate of $\mathrm{H}_{2} \mathrm{O}_{2}$ degradation by the action of CAT Contained in examined samples.

\subsection{Experimental design:}

The rats were randomly divided into four main groups: Group I: Administered orally normal saline for 6 weeks and act as a negative control group. Group II: Receive oral dose of Spirulina platensis (SP) at 1000 $\mathrm{mg} / \mathrm{kg} / \mathrm{b}$.wt. For 6 weeks and act as a Positive control group. Group III: receive intraperitoneal dose of (Doxorubicin $\mathrm{HCl}$ Solution) at $1 \mathrm{mg} / \mathrm{kg}$ b.wt for 6 weeks. Group IV: Receive intraperitoneal dose of (Doxorubicin $\mathrm{HCl}$ Solution) at $1.0 \mathrm{mg} / \mathrm{kg}$ 
b.wt. + (SP) at a dose of $1000 \mathrm{mg} / \mathrm{kg}$ b.wt. for 6 weeks.

\subsection{Sampling:}

Blood samples were collected after $3 \& 6$ weeks from onset of treatment from all animals groups (control and experimental groups) . Samples were collected from medial canthus of the eyes of all animal groups and were centrifuged at $3000 \mathrm{rpm}$ for 30 minutes to separate serum. Serum was kept in deep freezer till use for analysis of following biochemical parameters: Serum transaminases ALT and AST (Reitman and Frankel 1957). Serum urea (March et al., 1965). Superoxide dismutase (SOD) activity (Kakkar et al., 1984), and Catalase (CAT) Luck (1974).

\subsection{Statistical analysis:}

The Statistical analysis was carried out using $T$. test with two factors under significance level of 0.05 for the whole results using SPSS (ver. 22). Data were treated as complete randomization design according to Steel et al. 1997. Multiple comparisons were carried out applying.

\section{RESULTS}

Data in Table (1) represented that there is no significant difference in serum (ALT) content between group (G2) compared with group (G1) control either at first and second period. While, there is a very highly significant increase in serum ALT content for groups (G3), after first or last three weeks on the other hand, there is a highly significant decrease in ALT of G4 treated with Doxorubicin and Spirulina compared with G3. Regarding (AST), Data showed that there is a significant decrease in serum AST content between group (G2) compared with group (G1) at first and second period. Also, there is a highly significant increase in serum AST in G3 if compared with either G1 or G2 . Contrarily there is a very highly significant decrease in G4 group treated with Dox followed by Spirulina either after the first or last periods. Moreover data in Table (1) demonstrated that there is non significant decrease in serum urea content between group (G2) compared with group (G1) at first and second period. There is a significant increase in serum urea content for group (G3) which treated by Doxorubicin only compared with groups ( G1 or G2) at first and second period. But in group (G4), the addition of Spirulina to doxorubicin led to a decrease in serum urea content at first and second period. Data in Table (2) represented that there is no significant difference in serum (CAT) content between group (G2) compared with group (G1) at first and second period. There is a significant decrease in serum CAT content for groups $(\mathrm{G} 3, \mathrm{G} 4)$ which treated by Doxorubicin only or Doxorubicin with Spirulina compared with groups of control (G1 \& G2) at first and second period. But in group (G4) the addition of Spirulina with Doxorubicin led to increase serum CAT content compared with group (G3) of Doxorubicin treated rats only with 1.0 $\mathrm{ml} / \mathrm{kg}$ b.wt. at first and second period. Regarding SOD activity: Data presented in table ( 2) indicated that there is non significant difference in serum SOD content between group (G2) compared with group (G1) at first and second period. There is a significant decrease in serum SOD content for groups (G3, G4) which treated by Doxorubicin only or by Doxorubicin with Spirulina compared with groups of control ( G1 or G2 ) at first and second period. But in group (G4) the addition of Spirulina with Doxorubicin led to increase serum SOD content compared with group (G3) of Doxorubicin treated rats only with 1.0 $\mathrm{ml} / \mathrm{kg} \mathrm{b.wt}$. at first and second period.

\section{DISCUSSION}

Doxorubicin, a quinone-containing anthracycline antibiotic, is an important 
Table (1): Effects of spirulina platensis on Dox induced changes on rat serum ALT, AST activity and Urea content in rat Liver and Kidney.

\begin{tabular}{ccccc}
\hline Group & Time & $\begin{array}{c}\text { ALT } \\
(\text { unit } / 1)\end{array}$ & $\begin{array}{c}\text { AST } \\
(\text { unit } / 1)\end{array}$ & $\begin{array}{c}\text { Urea } \\
(\mathrm{mg} / \mathrm{dl})\end{array}$ \\
\hline G1 & First & $86.75 \pm 1.81$ & $110.5 \pm 2.15$ & $23.25 \pm 1.92$ \\
& Second & $79.75 \pm 1.15$ & $115.25 \pm 2.31$ & $24.75 \pm 1.11$ \\
G2 & First & $81.25 \pm 0.99$ & $93.25 \pm 1.19^{*}$ & $20.25 \pm 1.71$ \\
& Second & $75.50 \pm 1.92$ & $98.75 \pm 1.82^{*}$ & $22.25 \pm 1.31$ \\
G3 & First & $195.50 \pm 4.91^{* * *}$ & $229.77 \pm 5.19^{* * *}$ & $92.25 \pm 4.90^{* * *}$ \\
& Second & $202.11 \pm 5.11^{* * *}$ & $238.25 \pm 6.61^{* * *}$ & $95.51 \pm 4.00^{* * *}$ \\
G4 & First & $139.5 \pm 3.10^{* *}$ & $171.50 \pm 4.92^{* * *}$ & $68.25 \pm 3.15^{* * *}$ \\
& Second & $160.50 \pm 3.19^{* *}$ & $179.25 \pm 4.90^{* * *}$ & $71.25 \pm 3.30^{* * *}$ \\
\hline
\end{tabular}

*: Significant $(P<0.05), * *$ : High significant at $(P<0.01), * * *$ : Very high significant at $(P<0.001)$ Data are expressed as means $\pm \mathrm{SE}$.

Table (2): Effects of spirulina platensis on Dox induced changes on rat serum Catalase (CAT) and Superoxide Dismutase (SOD) activities in rat Liver and Kidney.

\begin{tabular}{cccc}
\hline Group & Time & $\begin{array}{c}\text { CAT } \\
(\mathrm{mmol} / \mathrm{g})\end{array}$ & $\begin{array}{c}\text { SOD } \\
(\mathrm{mmol} / \mathrm{g})\end{array}$ \\
\hline G1 & First & $25.73 \pm 2.17$ & $12.97 \pm 0.97$ \\
& Second & $27.98 \pm 2.00$ & $15.49 \pm 1.31$ \\
G2 & First & $26.41 \pm 2.90$ & $12.47 \pm 1.12$ \\
& Second & $28.91 \pm 2.92$ & $14.80 \pm 1.91$ \\
G3 & First & $5.65 \pm 1.31^{* * *}$ & $5.10 \pm 1.11^{* * *}$ \\
& Second & $4.87 \pm 1.11^{* * *}$ & $4.57 \pm 1.00^{* * *}$ \\
G4 & First & $11.13 \pm 2.15^{* *}$ & $7.97 \pm 1.31^{* *}$ \\
& Second & $9.50 \pm 1.39^{* *}$ & $7.66 \pm 0.99^{* *}$
\end{tabular}

*: Significant $(P<0.05), * *$ : High significant at $(P<0.01), * * *$ : Very high significant at $(P<0.001)$

agent against a wide spectrum of human neoplasms. However, its toxicity limits usage in cancer chemotherapy (Fadillioglu et al., 2003). Known for its metabolism and detoxification activity, the liver treats doxorubicin just like everything else. Thus, when a patient is being treated with the drug the liver that receives most of the drug, letting it accumulate and then metabolizing it. (Yang et al., 2002) By metabolizing the high concentrations of doxorubicin, a vast number of ROS are produced. Consequently, ROS causes an excessive amount of damage ranging from DNA damage, production of lipid peroxidation, decreasing vitamin $\mathrm{E}$ levels, decreasing reduced glutathione $(\mathrm{GSH})$. Data represented in Table (1) revealed that activities of serum AST, ALT were markedly elevated in doxorubicin treated groups compared to control group, indicating liver injury. The present results are in agreement with many authors as (Chen et al., 2004) who reported that, doxorubicin treated rats induce significant increases in ALT, AST and bilirubin serum levels when compared with the untreated control group. Our results are also consistent with the results reported by (Wilhelm et al., 1996) who demonstrated a higher activities of AST and ALT as recorded in the present study may be as a result of drastic conditions caused by the toxic activity and accumulation of doxorubicin in the liver and in turn this might provoke cellular destruction or 
increase the permeability of hepatic cells. In addition, (Injac et al. 2008) attributed the increase in the serum AST, ALT activities to their increased leakage from damaged and necrotic hepatocytes as a result of toxicity. Administration of Spirulina 1000 $\mathrm{mg} / \mathrm{kg}$ body weight, significantly $(P<0.01)$ lowered the elevation of AST and ALT serum enzymes induced by doxorubicin in relation to control groups (Table 1). The present study revealed the therapeutic activity of the Spirulina against well-known hepatotoxins produced by doxorubicin. Furthermore, (Luxia et al. 1996) reported that $\beta$-carotene of Spirulina may reduce cell damage, especially the damage to DNA molecules, thus playing the role in the repair of regeneration process of damaged liver cells. Doxorubicin is known to cause nephropathy and proteinuria by injuring glomerularpodocytes (Park et al., 2003). Doxorubicin-induced nephropathy occurs when the drug interferes with the normal functioning of the mitochondria, reducing the activity of complexes I and IV of the mitochondria. This causes the levels of triglycerides, superoxide and citrate synthase to increase, whilst levels of vitamin $\mathrm{E}$ and antioxidant compounds are reduced with lipid peroxidation occurring. The nephron structure is altered when leaked proteins from local passages come in contact with exposed renal tissue, ultimately leading to glomerulosclerosis. When the glomeruli becomes damaged it is unable to regulate the chemical composition of blood and unable maintain fluid balance causing hypertension, resistance to steroids and proteinuria, eventually leading to renal failure. (Carvalho et al., 2009). The elevation of serum urea level in the experimental groups was came in accordance with the results obtained by Ayla et al., (2011), and Abou Seif (2012) who showed that DOX caused a marked rise in serum urea, creatinine, sodium and potassium levels. In another renal injury study, spirulina at dose of $1000 \mathrm{mg} / \mathrm{kg}$ (similar to the dose used in our study) elicited significant reno protective activity by decreasing urea, while elevating reduced Glutathione (GSH), Glutathione peroxidase (GPx) and SOD levels indicating the therapeutic potential of spirulina (SP) against gentamicin sulphate induced nephrotoxicity and ROS production (Karadeniz et al., 2008). Data presented in Table (2) revealed that, a significant decreases in the activities of liver SOD and CAT in the doxorubicin treated animals as compared with their corresponding control values. . SOD plays an important role in protecting tissues against oxygen free radicals. SOD is a group of metalloenzymes that plays a crucial antioxidant role and constitutes the primary defense against the toxic effects of superoxide radical in aerobic organism (Kohen and Nyska, 2002). The generation of free radicals and decreased GSH levels significantly increased oxidative stress (Nagaraj et al., 2011). Injection of Doxorubicin $\mathrm{HCl}$ Solution at a dose of $1.0 \mathrm{mg} / \mathrm{kg}$ b.wt. resulted in depletion of glutathione (GSH ) and increase in oxidative stress. Adminstration of Spirulina significantly restored these enzymatic activities to be approximately near the normal limits in most of the cases. The C-phycocyanin has an excellent antioxidant property and scavenging free radicals like superoxide and hydroxyl radicals. The significant protection offered by C-phycocyanin demonstrated the radical scavenging activity and its inhibitory effect on lipid peroxidation chain reaction (Abdel-Daim et al., 2013). Moreover, (Karadeniz et al., 2009) found that Pre-treatment with Spirulina platenesis might play a role in reducing the toxic effect of cadmium and its antioxidant properties seemed to mediate such a protective effect, indicated by the reduction of MDA and NO as well as the elevation of GSH and SOD levels in liver tissue. It could be stated that addition of Spirulina with Doxorubicin increase in serum SOD content compared Doxorubicin only. These results run parallel to (Belay, 2002) who stated that Spirulina has direct effect on reactive oxygen species. 


\section{CONCLUSION}

Spirulina treatment ameliorates liver and kidney Injuries, which induced by Dox via free radical generation by decreasing the activities of biochemical parameters as (ALT, AST and urea) and increasing the activities of antioxidant parameters as (CAT and SOD ) restoring their levels to near normal. From the observed results, it concluded that combined treatment of doxorubicin and Spirulina holds promise as a safe and effective chemotherapeutic strategy.

\section{Acknowledgement}

Special Thanks for Center of Excellence in Scientific Research (CESR), fac. of vet. Med. Benha Univ. That funded by management supporting excellence (MSE) and Benha University

\section{REFERENCES}

Abdel-Daim, M.M., Abuzead, S.M.M., Halawa, S.M. 2013. Protective role of Spirulina platensis against acute deltamethrin-induced toxicity in rats. Plos one 8: e72991.

Abou Seif, H.S. 2012. Protective effects of rutin and hosperidin against Doxorubicin- induced Nephrotoxicity. Beni-Sueif University J. Applied Sci. 1(2):118.

Al-Shabanah, O., Mansour, M., El-Kashef, H., Al-Bekair, A. 1998a. Captopril ameliorates myocardial and hematological toxicities induced by adriamycin. Biochem. Mol. Biol. Int. 45: 419-427.

Al-Shabanah, O.A., Badary, O.A., Nagi, M.N., Al-Garably, N., Al-Rikabi, A., Al-Bekairi, A. M. 1998b. Thymoquinone protects against doxorubicin-induced cardiotoxicity without compromising its antitumor activity. J. Exp. Clin. Cancer Res. 17:193-198.
Ayla, S., Seckin, I., Tanriverdi, G., Cengiz, M., Eser, M., Soner, BC., Oktem, G. $2011 . \quad$ Doxorubicin Induced Nephrotoxicity: Protective Effect of Nicotinamide. International Journal of Cell Biology. 1-9. doi:10.1155/2011/390238.

Belay, A. 2002. The potential application of spirulina (Arthrospira) as a nutritional and therapeutic supplement in health management. JANA. 5:26-48.

Bopanna, K.N., Bhagyalakshmi, N., Rathod, S.P., Balaraman, R., Kannan, M. 1997. Cell culture derived Hemidesmus indicus in the prevention of hypercholesterolemia in normal and hyperlipidemic rats. Indian Journal of Pharmacology, 29(2): 105.

Carvalho, C. 2009. Doxorubicin: the good, the bad and the ugly effect. Curr Med Chem 16: 3267-3285.

Chen, H., Yu, Y.Y., Zhang, M.J., Deng, X.X., Yang, W.P., Ji., J., Peng, C.H., Li ,H.W. 2004. Protective effect of doxorubicin induced heat shock protein 72 on cold preservation injury of rat livers. World Journal Gastroenterol 10(9):1375-1378.

Chopra, K., Bishnoi, M. 2008. Antioxidant profile of Spirulina: a blue-green microalga. In Spirulina in Human Nutrition and Health. Edited by: Gershwin ME, Belay A. Boca Raton: CRC Press, 101-118.

Datla, P., Thomas, S.S. 2011. Parry Nutraceuticals, Division of EID, Parry (India) Ltd, Chennai, India.

Duda-Chodak, Aleksandra, Wajda, Lukasz, Kubica, Maria, Uniwersytet Gillick, J., Giles, S., Bannigan, J., Puri, P. 2002. Cell death in the early adriamycin rat model . Pediatr. Surg. Int. 18:576-580.

Duran, P.V., Juarez-Oropeza ,M.A. 2010. Protective effects of Spirulina maxima on hyperlipidaemia and oxidative-stress induced by lead 
acetate in the liverand kidney. Lipids in Health and Disease. 9:35.

Fadillioglu, E., Karaman, A., Turkmen, E., Tas, E., Yilmaz, Z. 2006. Protective effects of leflunomide against ischemia reperfusion injury of the rat liver. Pediatr. Surg. Int., 22:428434.

Gillick, J., Giles, S., Bannigan, J., Puri, P. 2002. Cell death in the early adriamycin rat model. Pediatr Surg Int. 18:576-580.

Granados-Principal, S., Quiles, J.L., Ramirez-Tortosa, C.L., SanchezRovira, P., Ramirez-Tortosa, M.C. 2010. New advances in molecular mechanisms and the prevention of Adriamycin toxicity by antioxidant nutrients. Food and Chemical Toxicology. 48:1425-1438.

Hayashi, K.1996a. Calcium-Spirulan, an inhibitor of enveloped virus replication, from a blue-green alga Spirulina. J. Nat. P. rod. 59:83-87.

Hayashi, K., Hayashi, K.T., Kojima, I. 1996b. A natural sulfated polysaccharide, Calcium-Spirulan, isolated from Spirulina platensis: in vitro and ex vivo evaluation of antiherpes simples virus and anti-human immunodeficiency virus activities. AIDS Res. Hum. Retroviruses. 12:1463-1471.

Hirahashi, T., Matsumoto, M., Hazeki, K., Saeki, Y.U.I. M., Seya, T. 2002. Activation of the human innate immune system by Spirulina augmentation of interferon production and NK Cytotoxicity by oral administration of hot water of Spirulina platensis. Int. Immunopharmacol 2:423-34.

Huang, Z., Guo, B. J., Wong, R.N.S., Jiang, Y. 2007. Characterization and antioxidant activity of seleniumcontaining phycocyanin isolated from Spirulina platensis. Food Chem. 100:1137-1143.

Injac, R., Strukelj, B. 2008. Recent Advances in Protection Against
Doxorubicin-induced Toxicity. Technology in Cancer Research and Treatment, 7:497-516

Kakkar, P., Das, B., Viswanathan, P.N.1984. A modified spectrophotometric assay of superoxide dismutase. Indian $\mathrm{J}$. Biochem. Biophys, 21:130-132.

Karadeniz, A., Yildirim, A., Simsek, N., Kalkan, Y., Celebi, F. 2008. Spirulina platensis protects against gentamicin-induced nephrotoxicity in rats. Phytother Res. 22:1506-1510.

Karadeniz, A., Cemek, M., Simsek, N. 2009. The effects of Panax ginseng and Spirulina platensis on hepatoxicity induced by cadmium in rats. Ecotoxicol Environ Safety.72:231-235.

Kohen, R.A., Nyska. 2002. "Oxidation of biological systems: oxidative phenomena, antioxidants, redox reactions, and methods forquantifications", Toxicol. Pathol., 30:620650.

Kulik, M.M. 1995. The Potential for using Cyanobacteria (blue greenAlgae) and algae in the biological control of plant pathogenic bacteria and fungi. European. J. Plant pathology. 101(6):585-599.

Luck, H. 1974. Estimation of catalase. In: methods in enzymatic analysis. Second edition, Bergmeyer, Academic Press, New York. 885-890.

Luxia, A.S., Monica, S., Ornella, C., Pizzala, B., Loura, R., Livia, B., Anio, M., Ennio, P. 1996. Effect of Bcarotene on cell cycle progression of human fibroblasts. Mutagenesis, 17:2395-2401.

March, W.H., Fingerhut, B., Miller, H. 1965. Clinical chemistry. 11:624-627.

Nakaya, N., Honma, Y., Goto, Y. 1988. Cholesterol lowering effect of Spirulina. Nutr. Rep. Int., 37:13291337.

Nagaraj, S., Arulmurugan, P., Karuppasamy, K., Jayappriyan, K.R., Sundararaj, R., Vijayanand, N., 
Rengasamy, $\quad$ R. 2011. Hepatoprotective and antioxidative effects of C-Phycocyanin in CCL4 induced hepatic damage rats. Academic Journal of Cancer Research 4:29-34.

Park, E. 2003. Protective effects of Nacetylcysteine and selenium against doxorubicin toxicity in rats. J Vet Sci 4: 129-136.

Pedrycz, A., Wieczorski, M., Czerny, K. 2004. Theinfluence of a single dose of adriamycin on thepregnant rat female liver- histological andhistochemical evaluation. Ann. Univ. Mariae. Curie. Sklodowska. 5:319-323

Pedrycz A., Wieczorski, M., Czerny, K. 2004. Increased apoptosis in the rat liver after a singledose of adriamycin administration. Annales. UMCSSect D. 59:313- 318 .

Pedrycz, A., Boratynski, Z., Wieczorski, M.,Visconti, J. 2005. Ultrastuctural and immunohistochemical evaluation of apoptosis infetal rat liver after adriamycin administration. BullVet .Inst .Pulawy. 49:475-479

Ponce-Canchihuaman, J.C., Perez-Mendez, O., Hernandez-Munoz, R., TorresDurán, P.V., Juárez-Oropeza, M.A. 2010. Protective effects of Spirulina maxima on hyperlipidemia and oxidative-stress induced by lead acetate in the liver and kideny. Lipid in Health and disease 9: 35.
Quiles, J.L., Huertas, J.R., Battino, M., Mataix, J., Ramirez-Tortosa, M.C. 2002. Antioxidant nutrients and Adriamycin toxicity. Toxicology. 180:79-95.

Reitmans, S., Frankel, S. 1957. ReitmanFrankel colourimetric method of Got/ As $\mathrm{T}$ and GPT/ALT Tromsaminales. Am. J. Clin. Path. 28:56-63.

Steel, R., Torrie, J., Dickey, D. 1997. Principles and procedures of Statistics: A Biometrical Approach, 3rd ed., McGraw-Hill, New York, NY.

Wilhelm, M., Jaeger, D.E., Schall-Cablitz, H., Hafner D., Idel, H. 1996. Hepatic clearance and retention of aluminum: studies in the isolated perfused rat liver. Toxicol. Lett 89(3):257-263.

Yilmaz, S., Atessahin, A., Sahna, E., Karahan, I., Ozer, S. 2006. Protective effect of lycopene onadriamycininduced nephrotoxicity and nephrotoxicity. Toxicology. 218:164171.

Yang, X. 2002. Photo-induced cytotoxicity of malonic acid [C60] fullerene derivatives and its mechanism. Toxicol in Vitro 16: 41-46. 